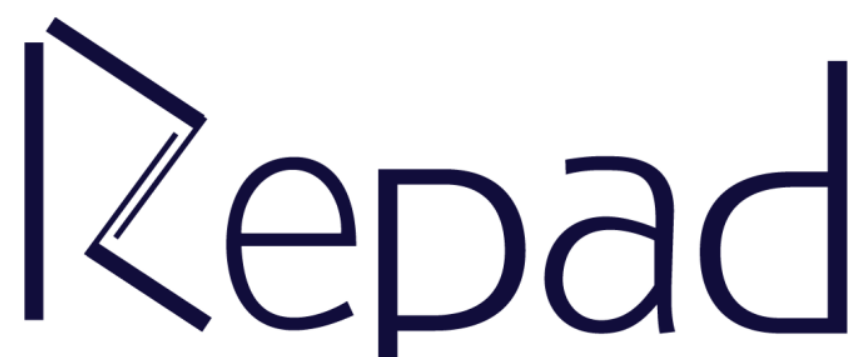

Vol. 2, n 2, AGOSTO//2018

Revista Estudos e

Pesquisas em Administração

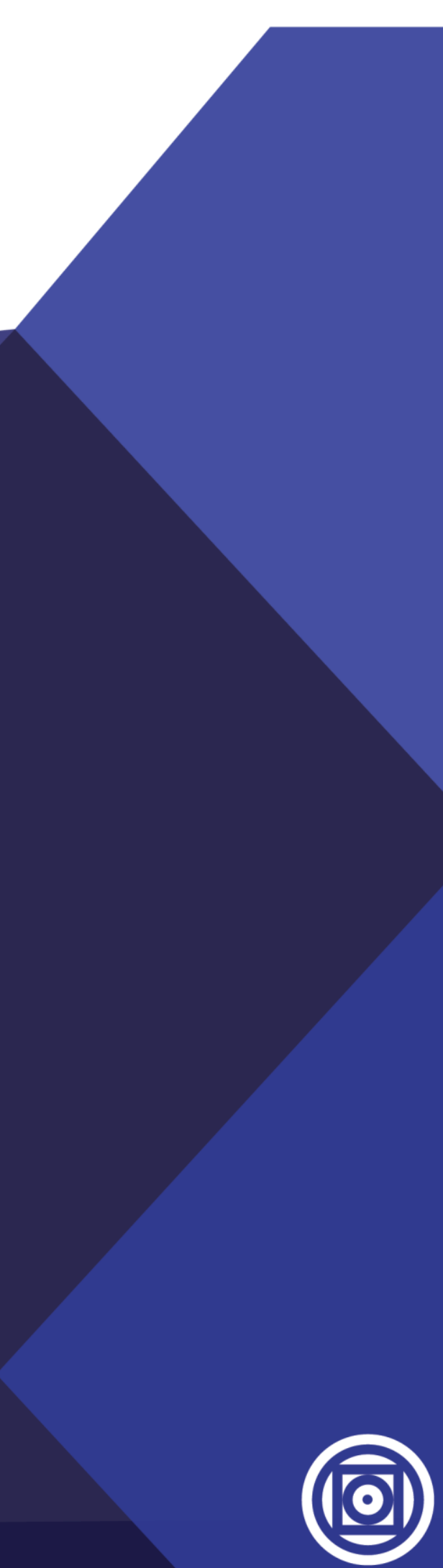




\title{
TERCEIRIZAÇÃO NAS INSTITUIÇÕES FEDERAIS DE ENSINO SUPERIOR: O processo de licitação para os serviços terceirizados da Universidade Federal de Pernambuco
}

\section{OUTSOURCING IN FEDERAL INSTITUTIONS OF HIGHER EDUCATION: The bidding process for the outsourced services of the Federal University of Pernambuco}

\author{
Jose de Arimathea Cabral \\ Universidade Federal de Pernambuco \\ https://orcid.org/0000-0002-2807-0874
}

\begin{abstract}
RESUMO
A Constituição Federal estabelece que toda contratação pública deve ser realizada através da licitação. Este trabalho apresenta uma análise sobre os procedimentos para as contratações públicas dos serviços terceirizados nas instituições federais de ensino superior, tomando como referência os processos de contratações de serviços terceirizados, na Universidade Federal de Pernambuco. No desenvolvimento do trabalho, tomou-se com referencial teórico os conceitos de licitação, expondo um breve histórico da licitação pública e as legislações que regulam as contratações públicas. Para isso, percorreu o caminho metodológico da abordagem qualitativa por meio de pesquisa bibliográfica e documental, tendo a base teórica sido fundamentada em trabalhos já publicados e pertinentes ao tema da pesquisa e nas legislações regulatórias da licitação pública. O resultado alcançado foi produto de pesquisa documental realizada na unidade administrativa Diretoria de Licitação e Contratos que é subordinada à Pró Reitoria de Gestão Administrativa da UFPE, onde foram analisados os processos de contratação de empresas especializadas na prestação de serviços. Da análise, verifica-se que a contratação pública não é tarefa simples e não se concretiza em tempo hábil e que requer profundo conhecimento das partes envolvidas e ainda enfrenta uma burocracia lenta e onerosa.
\end{abstract}

Palavras-chave: Contratação Pública; Serviços Terceiros; Gestão Pública

\begin{abstract}
The Federal Constitution establishes that all public contracts must be carried out through bidding. This paper presents an analysis of the procedures for contracting public outsourced services in federal institutions of higher education, taking as reference the contracting processes of outsourced services, at the Federal University of Pernambuco. In the development of the work, the concepts of bidding were taken as theoretical reference, exposing a brief history of the public bidding and the legislations that regulate the public hirings. For that, the qualitative approach was carried out through bibliographical and documentary research, and the theoretical basis was based on papers already published and pertinent to the research topic and in the regulatory legislation of public bidding. The result was a documentary research product carried out at the Administrative Unit for Procurement and Contracts, which is subordinated to the UFPE Administrative Management Office, where the processes of hiring companies specialized in the rendering of services were analyzed. The analysis shows that public procurement is not a simple task and does not take place in a timely manner and requires deep knowledge of the parties involved and still faces a slow and burdensome bureaucracy.
\end{abstract}

Keywords: Public Procurement; Third Party Services; Public Administration 


\section{INTRODUÇÃO}

A Constituição Federal, no seu artigo 37, estabelece que as contratações da administração pública só podem ser realizadas mediante do processo de licitação pública cujo procedimento é complexo e minucioso, que requer um aparelhamento e profundo conhecimento das partes envolvidas no processo.

Ao adquirir, locar bens, contratar a execução de obras ou serviços, o Poder Público, em atendimento aos princípios constitucionais e na busca da proposta mais vantajosa, necessita adotar procedimento rigorosamente determinado e preestabelecido, de forma a manter as condições de igualdade entre os concorrentes.

Da mesma maneira que as empresas e famílias procuram o mercado para suprir suas necessidades por produtos ou serviços, estabelecendo critérios que podem ser o menor preço, qualidade dos produtos ou confiabilidade do fornecedor, para escolher de quem contratar, o Estado também vai ao mercado com seus critérios para escolher os fornecedores de bens e serviços de que necessita.

De acordo com o conteúdo dos cursos do ENAP (2014), as grandes empresas formalizam os seus critérios nos regulamentos internos e em se tratando do Estado, os critérios para contratação estão previstos na Constituição e nas leis. Tudo o que o Estado compra ou contrata deve ter conhecimento público e por isso é previamente divulgado, de maneira que todos os interessados possam concorrer e serem fornecedores do Estado, de um procedimento administrativo denominado de licitação.

A licitação é considerada por Silva e Carvalho (2017) como um dos principais meios de critério da aplicação dos recursos públicos e assim o processo das contratações do governo é envolvido em ampla publicidade, mas não o suficiente para a sociedade ter o conhecimento e a noção da dimensão da estrutura burocrática necessária às atividades das contratações governamentais.

Por outro lado, os estudos de Fonseca, Gusinsky e Bernardes (2014) apontam que os atos da Administração Pública consideram o bem geral e devem estar acima de quaisquer interesses privados e serem pautados pelos princípios da legalidade, impessoalidade, moralidade, igualdade, publicidade e eficiência. Nesse sentido, é relevante discutir os procedimentos prévios das contratações públicas, de modo a ajudar na transparência das contrações de serviços terceirizados, principalmente no caso daqueles que são executados com dedicação exclusiva de mão de obra.

Diante desse contexto, surge o questionamento: Como é estruturado e planejado o processo de licitação para contratação de serviços na UFPE?

A respeito desse questionamento, foi realizada uma pesquisa no acervo bibliográfico da UFPE e foram encontrados poucos trabalhos acadêmicos a respeito do tema terceirização e com conteúdos escassos com referência aos procedimentos de contratação para a execução das atividades acessórias da Instituição.

$\mathrm{O}$ artigo, desenvolvido por intermédio de pesquisa bibliográfica e documental em trabalhos pertinentes ao tema e nas legislações especificas, pretende descrever de que forma são aplicadas as regras que asseguram as condições de igualdades entre os concorrentes, no processo de licitação para a contratação de serviços terceirizados com dedicação exclusiva de mão de obra na UFPE.

Utilizando-se o método qualitativo, o estudo foi desenvolvido mediante de análise de documentação disponível na Diretoria de Licitação e Contratos (DLC), setor vinculado à Pro Reitoria de Gestão Administrativa da UFPE (PROGEST) que é responsável pela gestão de licitações, contratos, patrimônio móvel, serviços, compras, importação e materiais. 
A escolha do tema foi pela necessidade de conhecer melhor os procedimentos e como são desenvolvidos o processo de contratação de serviços terceirizados e ampliar o conhecimento da sociedade em relação a estas contratações públicas e estimular novas pesquisas, tendo em vista que o tema é pouco explorado na comunidade acadêmica da UFPE.

\section{REFERENCIAL TEÓRICO}

\section{LICITAÇÃO - CONCEITOS}

A licitação é um procedimento, que a Administração Pública utiliza para adquirir produtos ou serviços necessários para a realização de suas atividades e como se trata de utilização de recursos públicos, deve seguir critérios estabelecimento pela lei.

Na concepção de Oliveira, Almeida e Lopes (2013), a Administração Pública nem sempre dispõe de meios próprios para prover as necessidades da coletividade, no cumprimento da sua missão de gerenciar os serviços públicos, por isso se vê obrigada a adquirir bens, serviços e obras junto à iniciativa privada cujas contratações só podem ser celebradas por processo licitatório, conforme estabelecido no Art. 37 da Constituição Federal de 1988 e que seja assegurada a igualdade de condições entre os concorrentes.

Silva e Carvalho (2017), fundamentado no art. 23 da Lei 8.666/93 ${ }^{1}$,definem licitação como o procedimento administrativo para contratação de serviços ou aquisição de produtos pelo governo, tendo como objetivo a igualdade, transparência e legitimidade e que estas práticas administrativas devem ser orientadas para a busca do interesse público como objetivo final. Os mesmos autores ainda consideram o processo licitatório como sendo um dos principais meios de critério da aplicação dos recursos públicos, tendo em vista que, observando as condições de igualdade entre os concorrentes, busca a proposta mais vantajosa para contratação por parte do poder público.

Faria e Oliveira (2016), em suas análises sobre a utilização da licitação pública na modalidade pregão eletrônico, apresentam o vocábulo "licitação" como termo derivado do latim Licitatione cuja finalidade é arrematar em leilão após a formalização de lances. Para os autores, licitação é o procedimento das contratações públicas regulamentado com normas gerais pela Lei $n^{\circ} 8.666 / 93$.

Neste sentido, podemos dizer que as propostas apresentadas para as contratações do governo seriam como os lances de um leilão, e o arremate da contratação seria da proposta mais vantajosa, após o atendimento dos critérios, previamente, estabelecidos, como mostra o conceito definido pela ENAP (2014):

É o procedimento administrativo preliminar, mediante o qual a Administração, baseada em critérios prévios, seleciona, entre várias propostas referentes a compras, obras ou serviços, a que melhor atende ao interesse público, a fim de celebrar contrato com o responsável pela proposta mais vantajosa, em observância ao princípio constitucional da isonomia.

Outros autores dão maior robustez na conceituação de licitação, estendendo a definição até na capacitação dos proponentes, como na definição dos autores Reitz Júnior e Boselli (2016):

\footnotetext{
${ }^{1}$ Lei que regulamentou o art. 37 da Constituição Federal e instituiu normas gerais para a Licitação.
} 
As contratações na Administração Pública são regidas pela Lei no 8.666, de 21 de junho de 1993 e legislações correlatas, que além de instituírem as modalidades de licitação trazem uma regulamentação apropriada e robusta a fim de garantir a isonomia, assegurando a igualdade entre todos os participantes, selecionando a proposta mais vantajosa para a administração por meio de ampla disputa envolvendo maior número de participantes capacitados a fim de atender o interesse público.

Comparando todos os conceitos, podemos concluir que licitação é o conjunto de procedimentos administrativos para as contratações do governo, nas esferas federal, estadual, distrital e municipal. Neste sentido, no desenvolvimento do presente trabalho, a licitação pública será entendida como uma competição entre os fornecedores interessados nas contratações do governo, por meio de um processo formal e com regras definidas em lei.

A licitação, como forma de contratação pública, vem de uma evolução histórica conforme demonstra o tópico a seguir.

\section{BREVE HISTÓRICO}

Antes da Constituição de 1988, as contratações públicas eram regidas por Decreto ou Lei especifica. A seleção da proposta mais vantajosa para a Administração não seguia os princípios da isonomia e da igualdade perante a lei. Prevalecia o caráter discricionário administrativo, onde o processo de contratação atendia o interesse financeiro do Estado em obter menor preço.

A contratação pública, segundo estudos da ENAP (2014), veio com o Código de Contabilidade Pública da União, organizado pelo Decreto ${ }^{\circ} 4.536$, de 19 de janeiro de 1922 e posteriormente pela Lei $\mathrm{n}^{\circ} 4.401 / 64$, mas não focava os princípios da isonomia e da igualdade de todos perante a lei, na seleção da proposta mais vantajosa. Nesta época, o processo de contratação era denominado de concorrência e visava atender ao interesse financeiro do Estado em obter o preço mínimo. De acordo com os estudos da ENAP (2014), o caráter discricionário administrativo do processo de contratação só foi retirado com a Reforma Administrativa Federal, em 1967, por intermédio do Decreto-lei $\mathrm{n}^{\circ} 200$ que transformou o processo de contratação em instituto vinculante e obrigatório, no âmbito da administração federal e mais tarde, através da Lei ${ }^{\circ}$ 5.456/68 estendeu tal obrigatoriedade para os Estados e Municípios.

As licitações e contratos públicos da administração federal eram regidos pelas regras estabelecidas no Decreto-lei n ${ }^{\circ} 2.300$, de 21/11/1986, que também estendeu sua aplicabilidade para os Estados, Municípios e Distrito Federal, porém, somente com a Constituição de 1988, que instituiu os princípios da Administração Pública, foi que a licitação se tornou obrigatória para toda a Administração Pública (ENAP, 2014).

A garantia da observância desses princípios, no processo de contratação pública, foi dada com a regulamentação da licitação através da Lei $n^{\circ}$ 8.666/93. Assim, na seleção da proposta mais vantajosa para a administração, a licitação é processada e julgada em estrita conformidade com os princípios básicos da legalidade, impessoalidade, da moralidade, da igualdade, da publicidade, da probidade administrativa e da vinculação ao instrumento convocatório (Lei 8.666/93).

A obrigatoriedade da licitação, instituída pela Carta Magna de 1988, para as contratações públicas, permitiu maior publicidade nos processos de aquisições do setor público e mais objetividade nos critérios adotados que devem obedecer aos princípios básicos, definidos na Constituição. É o que se pode notar com as atuais regras que disciplinam a licitação pública. 


\section{LEGISLAÇÃO E INSTRUMENTOS REGULATÓRIOS DA LICITAÇÃO PÚBLICA}

O processo de licitação é regido pela Lei 8.666/93 que regulamentou o art. 37 da Constituição Federal de 1988 e pela Lei 10.520/2002, instituidora da modalidade de licitação denominada pregão. Há também alguns diplomas normativos que disciplinam pontos específicos e complementares do Estatuto de Licitações (ENAP, 2014), por exemplo, a Instrução Normativa ${ }^{\circ}$ 02/2008, de 30 de abril de 2008, do Ministério do Planejamento, que dispõe sobre regras, diretrizes e procedimentos para a contratação de serviços em geral. No desenvolvimento do artigo, estas legislações e normas foram abordadas de forma a esclarecer as regras que viabilizam a melhor contratação para o Poder Público.

\section{Lei 8.666/93}

Editada em 21 de junho de 1993, a Lei 8.666/93 regulamentou o inciso XXI do artigo 37 da Constituição Federal e estabeleceu normas gerais sobre licitações e contratos administrativos com referência a compras, obras, serviços, inclusive publicidade, alienações e locações no âmbito dos Poderes da União, dos Estados, do Distrito Federal e dos Municípios. Além de estabelecer que nenhum contrato pode ser celebrado com a administração pública sem antes passar pelo processo de licitação, ressalvadas as hipóteses de dispensa e de inexigibilidade de licitação.

Segundo o Tribunal de Contas da União (2010), esta lei tem o objetivo de garantir a observância do princípio constitucional da isonomia e selecionar a proposta mais vantajosa para a Administração, assegurando igual oportunidade a todos os interessados, possibilitando o comparecimento ao certame de maior número de concorrentes.

Modalidades de Licitação

A modalidade indica como irá reger o procedimento da licitação. A Lei 8.666/93 institui como modalidades de licitação o Convite, Tomada de Preços, Concorrência, Leilão, Concurso e a Lei 10.520/2002, que será analisada em outro tópico, criou a modalidade do Pregão. Nestas modalidades, a legislação estabelece qual o tipo de licitação para avaliar e julgar as propostas, quais sejam: menor preço, melhor técnica, técnica e preço e maior lance ou oferta quando se tratar de alienação de bens ou concessão de uso de bens públicos. Na modalidade concurso não se aplicam os tipos de licitação definidos pela lei (FARIA; OLIVEIRA, 2016). O concurso deve ter seus critérios de julgamento estabelecidos de acordo com o seu objeto. A seguir, conceitos gerais sobre as modalidades de licitação (TRIBUNAL DE CONTAS DA UNIÃO, 2010), além de limites por modalidade expostos no Quadro 1.

Concorrência: Podem participar quaisquer interessados que na fase de habilitação preliminar comprovem possuir os requisitos mínimos de qualificação exigidos no edital para execução do objeto da licitação.

Tomada de preços: Modalidade de licitação entre interessados devidamente cadastrados ou que atenderem a todas as condições exigidas para cadastramento até o terceiro dia anterior à data do recebimento das propostas, observada a necessária qualificação.

Convite: Modalidade realizada entre interessados do ramo de que trata o objeto da licitação, cadastrados ou não, escolhidos e convidados em número mínimo de três pela Administração. É a modalidade de licitação mais simples, onde a Administração escolhe quem quer convidar, entre os possíveis interessados. A divulgação é feita mediante afixação de cópia do convite em quadro de avisos do órgão ou entidade, localizado em lugar de ampla divulgação. É possível a participação de interessados que não tenham sido formalmente convidados, desde 
que sejam do ramo do objeto licitado e estejam cadastrados no órgão ou entidade licitadora ou no Sistema de Cadastramento Unificado de Fornecedores - SICAF ou cadastro unificado similar, mas devem solicitar o convite com antecedência de 24 horas da apresentação das propostas.

Concurso: É a modalidade de licitação entre quaisquer interessados para a escolha de trabalho técnico, científico ou artístico, mediante a instituição de prêmios ou remuneração aos vencedores, conforme critérios constantes de edital publicado na imprensa oficial com antecedência mínima de 45 (quarenta e cinco) dias.

Leilão: Modalidade realizada entre quaisquer interessados para a venda de bens móveis inservíveis para a Administração ou de produtos legalmente apreendidos ou empenhados, ou para a alienação de bens imóveis previstas no art. 19 da Lei 8.666/93, a quem oferecer o maior lance, igual ou superior ao valor da avaliação.

Pregão: É a modalidade de licitação realizada entre interessados do ramo do objeto definido no edital, em que a disputa pelo fornecimento de bens ou serviços comuns é feita em sessão pública, podendo ser presencial ou eletrônico. Os licitantes apresentam as propostas de preço por escrito e por lances, que podem ser verbais ou na forma eletrônica.

Quadro 1. Resumo dos valores limites das modalidades tradicionais

\begin{tabular}{|l|l|l|}
\hline \multicolumn{1}{|c|}{ Modalidades } & \multicolumn{1}{|c|}{$\begin{array}{c}\text { Obras e Serviços de } \\
\text { Engenharia }\end{array}$} & \multicolumn{1}{c|}{ Compras e Serviços } \\
\hline Concorrência & Acima de R $\$ 1.500 .000,00$ & Acima de R $\$ 650.000,00$ \\
\hline Tomada de Preços & Até R $\$ 1.500 .00,00$ & Até R $\$ 650.000,00$ \\
\hline Convite & Até R $\$ 150.000,00$ & Até R $\$ 80.000,00$ \\
\hline Pregão & $\begin{array}{l}\text { Independe de valores, mas é exclusivamente destinado à } \\
\text { contratação de bens e serviços comuns. }\end{array}$ \\
\hline
\end{tabular}

Fonte: Leis 8.666/93 e 10.520/2002

\section{Lei $10.520 / 2002$}

Promulgada em 17 de julho de 2002, esta lei instituiu, no âmbito da Administração Pública, a modalidade de licitação denominada Pregão, simplificando os procedimentos burocráticos, nas contratações públicas de bens e serviços comuns. Isto ocorre porque no Pregão não há limites de valores como nas demais modalidades e a ordem de habilitação e classificação das propostas é invertida, isto é, primeiro toma-se conhecimento do valor ofertado e somente depois que se verificam as condições de habilitação da empresa vencedora para contratar com o Poder Público.

Na Administração Federal é obrigatório o uso do Pregão para contratação de bens e serviços comuns, havendo inviabilidade de sua utilização, o dirigente ou a autoridade competente deve apresentar as justificativas, de forma motivada e circunstanciada.

Diante do avanço das tecnologias da informação, o Decreto ${ }^{\circ} 5.450$, de 31 de maio de 2005, regulamentou o Pregão Eletrônico, possibilitando a realização de licitação por meio da internet, permitindo maior transparência, maior número de participantes, maior agilidade no processo e favorecendo a competição (FONSECA; GUSINSKY; BERNARDES, 2014).

Esta lei instituidora da modalidade de licitação Pregão não dispõe de todas as normas para conduzir um processo de licitação. A esse respeito, Fonseca, Gusinsky e Bernardes (2014) apontam que o próprio legislador reconheceu esta lacuna, ao estabelecer no Art. $9^{\circ}$ a aplicação subsidiariamente das normas da Lei 8.666/93 para a modalidade Pregão, ou seja, a Lei 10.520/2002, segundo Faria e Oliveira (2016), contém apenas considerações básicas dos procedimentos do Pregão. Mas os autores Fonseca, Gusinsky e Bernardes (2014) avançam na explicação da duplicidade de aplicação da lei nesta modalidade de licitação, ao afirmarem: 
Portanto, para o pregão, em princípio, deve-se obedecer a Lei nº 10.520/2002. Em situações em que esta for omissa, recorre-se às normas da Lei $\mathrm{n}^{\circ}$. 8.666/1993. No caso de contradição entre as duas Leis, deve prevalecer a Lei $\mathrm{n}^{\circ}$. 10.520/2002, porque seu conteúdo versa precisamente sobre pregão (FONSECA; GUSINSKY; BERNARDES, 2014).

O procedimento licitatório da modalidade Pregão é realizado em duas grandes fases, a interna e externa. Na fase interna, a Administração dá início ao processo licitatório, justificando e caracterizando o objeto a ser contratado. É nesta fase que se elabora o Termo de Referência, estabelecendo os critérios para a contratação com o serviço público e estimando os custos da contratação e posteriormente definir o instrumento convocatório. Esta fase é também, chamada de preparatória e os detalhes estão definidos no Art. $3^{\circ}$ da Lei 10.520/2002.

A fase externa é onde ocorre a competição para a seleção da proposta mais vantajosa. Seu início é caracterizado pela publicação do edital e a disponibilização do instrumento completo aos interessados. Esta fase se encerra com a adjudicação do objeto e homologação do processo licitatório. A sequência dessa fase é detalhada no Art. $4^{\circ}$ da Lei do Pregão.

Na visão de Fonseca, Gusinsky e Bernardes (2014), o Pregão Eletrônico é uma ferramenta dinâmica para processar as aquisições de bens e contratações de serviços na Administração. Para Faria e Oliveira (2016), a inclusão da modalidade Pregão foi um avanço nas licitações públicas e sua forma eletrônica trouxe benefícios da tecnologia para as contratações no âmbito do poder público.

\section{Instrução Normativa $n^{\circ} 02 / 2008$}

A Secretaria de Logística e Tecnologia da Informação, órgão vinculado ao Ministério do Planejamento, editou a Instrução Normativa nº 02/2008, em 30/04/2008 (IN 02/2008), para disciplinar a contratação de serviços, continuados ou não, mais precisamente as terceirizações, no âmbito do Governo Federal. Esta Instrução Normativa, segundo Santana (2008), trouxe para o cenário da licitação preceitos já mencionados em lei, doutrina e jurisprudência, o que não deixa de ser uma boa contribuição para o processo de licitação. $\mathrm{O}$ mesmo autor sugere o uso desta norma para outras esferas públicas que queiram praticar uma boa gestão pública.

Com o intuito de boas práticas administrativas, a IN 02/2008, no seu Art. $2^{\circ}$. trouxe como novidade o planejamento para as contratações públicas o qual deve estar em harmonia com o planejamento estratégico da instituição e ainda estabelecer produtos ou resultados a serem obtidos com a respectiva contratação. Daí o motivo da IN 02 dedicar do Art. 14 ao Art. 17 para estabelecer regras para a elaboração do Termo de Referência ou Projeto Básico.

Para facilitar a compreensão dos temas tratados na IN 02/2008, Santana (2008) elaborou o Quadro 2.

Em 26 de maio de 2017, o Ministério do Planejamento editou a Instrução Normativa ${ }^{\circ}$ 05/2017 contendo novas regras e diretrizes no procedimento de contratação de serviços sob o regime de execução direta na Administração Pública Federal, revogando a IN nº 2/2008. Porém, como regra de transição, a norma estabeleceu o prazo de 120 dias para sua entrada em vigor, assim os procedimentos administrativos autuados ou registrados até a data de entrada em vigor da $\mathrm{IN} \mathrm{n}^{\circ} 05 / 2017$ permanecem regidos pela regra antiga. 
Quadro 2. Sumário da IN 02/2008

\begin{tabular}{|l|l|}
\hline \multicolumn{1}{|c|}{ TEMAS } & \multicolumn{1}{c|}{ DISPOSITIVOS LEGAIS } \\
\hline Disposições Gerais & Artigos $1^{\circ}$ a $5^{\circ}$ \\
\hline Da Terceirização & Artigos $6^{\circ}$ a 13 \\
\hline Do Projeto Básico ou Termo de Referência & Artigos 14 a 17 \\
\hline Do Instrumento Convocatório & Artigos 18 a 20 \\
\hline Das Propostas & Artigos 21 a 24 \\
\hline Do Julgamento das Propostas & Artigos 25 a 29 \\
\hline Da Vigência dos Contratos & Artigo 30 \\
\hline $\begin{array}{l}\text { Do Acompanhamento e Fiscalização da } \\
\text { Execução dos Contratos }\end{array}$ & Artigos 31 a 35 \\
\hline Do Pagamento & Artigo 36 \\
\hline Da Repactuação & Artigos 37 a 41 \\
\hline Dos Serviços de Limpeza e Conservação & Artigos 42 a 48 \\
\hline Dos Serviços de Vigilância & Artigos 49 a 51 \\
\hline Das Disposições Finais & Artigos 52 a 57 \\
\hline Anexo I & Glossário \\
\hline Anexo II & Modelo do Acordo de Nível de Serviço \\
\hline Anexo III & Planilha de custos e formação de preços \\
\hline Anexo III A & Mão de Obra \\
\hline Anexo III B & Demais Custos \\
\hline Anexo III C & $\begin{array}{l}\text { Quadro com detalhamento de encargos sociais e } \\
\text { trabalhistas }\end{array}$ \\
\hline Anexo IV & $\begin{array}{l}\text { Guia de fiscalização dos contratos de } \\
\text { terceirização }\end{array}$ \\
\hline Anexo V & $\begin{array}{l}\text { Metodologia de referência dos serviços de } \\
\text { limpeza e conservação }\end{array}$ \\
\hline Anexo VI & $\begin{array}{l}\text { Metodologia de referência dos serviços de } \\
\text { vigilância }\end{array}$ \\
\hline
\end{tabular}

Fonte: Santana (2008)

\section{PROCEDIMENTOS DO PROCESSO LICITATÓRIO}

As regras para abertura da licitação estão definidas no Art. 38 da Lei 8.666/93. Portanto o procedimento da licitação tem início com a abertura do processo administrativo, onde os autos são autuados, protocolados e numerados, contendo a respectiva autorização, a indicação resumida do seu objeto e a indicação orçamentária relativa à despesa. Outros documentos estabelecidos pela legislação serão juntados oportunamente.

O Licitacao.net (2012) indica que a licitação se inicia por uma necessidade da administração pública, onde é planejado o que e como contratar e comprar, etapa denominada fase interna da licitação, momento em que o objeto a ser contratado é especificado e as regras para a contratação são estabelecidas, dando corpo ao ato convocatório, denominado edital da licitação que ao ser publicado marca o início da fase externa da licitação, disponibilizando aos interessados o instrumento com os requisitos mínimos e necessários para participarem do certame. A fase externa se encerra com a homologação do vencedor do certame a quem cabe o Poder Público adquirir o bem ou formalizar a contratação do serviço (LICITACAO.NET, 2012).

Na licitação modalidade Pregão, o Termo de Referência é a base para a elaboração do instrumento convocatório que consiste no ato administrativo que dá publicidade à licitação, convocando os interessados para a disputa e fixando as regras indispensáveis para o processamento do procedimento licitatório (FONSECA, 2014). Com a publicação do 
instrumento convocatório, fica disponibilizado aos interessados o edital contendo todos os requisitos para a contratação pública.

O edital é um documento, específico para cada licitação, onde estarão todas as regras estabelecendo as condições para a contratação do Poder Público e que serão observadas pela Comissão de Licitação na condução do processo licitatório. Não pode conter cláusulas ou condições que inibem a competição. Deve definir, claramente, o objeto a ser licitado e os requisitos ou condições necessárias ao fornecedor do produto ou serviço a ser contratado. Compõe o edital os anexos tais como projeto executivo, minuta de contrato, modelo de declarações e documentos complementares e ainda especificação do local de entrega do produto, local de execução dos serviços e seu prazo de execução e outras exigências legais (OLIVEIRA, ALMEIDA, LOPES, 2013).

O edital é a lei interna da licitação, uma vez publicado, só pode ocorrer alteração, fazendo nova publicação e se a alteração for relacionada com as condições da proposta, é necessário reabrir o prazo para a apresentação das mesmas. As regras fixadas no edital devem ser obedecidas por todos, inclusive pela Administração por estar estritamente vinculada ao edital, conforme estabelecido no art. 41 da Lei 8.666/93.

Com a regulamentação da licitação pública, todos têm a oportunidade em contratar com a Administração Pública, seguindo os procedimentos formalizados pela Lei 8.666/93 e outras legislações complementares. A melhor proposta para a Administração Pública é selecionada, numa competição onde todos participem sem nenhuma diferenciação.

Neste estudo procurou verificar a legislação reguladora das contratações públicas e o procedimento da licitação, utilizando-se da pesquisa bibliográfica e documental, cuja metodologia está exposta na próxima seção.

\section{PROCEDIMENTOS METODOLÓGICOS}

Segundo Gil (2002) para descrever os procedimentos na realização da pesquisa, é preciso esclarecer a natureza da pesquisa e seu delineamento que pode ser definido em dois grandes grupos: os que se valem das chamadas fontes de "papel” e daqueles cujos dados são fornecidos por pessoas. O primeiro grupo é constituído pela pesquisa bibliográfica e a pesquisa documental e o segundo grupo compõe a pesquisa experimental, ex-post facto, levantamento e estudo de caso. Na concepção do autor "a pesquisa bibliográfica é desenvolvida com base em material já elaborado, constituído principalmente de livros e artigos científicos". Quanto à pesquisa documental, o autor não a define por ver semelhanças com a pesquisa bibliográfica onde a única diferença está na natureza das fontes. Segundo Gil (2002), se na pesquisa bibliográfica utiliza-se das contribuições dos diversos autores sobre determinado tema, na pesquisa documental utiliza-se de materiais que ainda não receberam tratamento analítico.

Neste sentido, quanto aos fins, a pesquisa será classificada como descritiva, em razão de expor as características do processo de licitação para serviços terceirizados da Universidade Federal de Pernambuco. Quanto aos meios será utilizada a pesquisa bibliográfica e documental, uma vez que a pesquisa bibliográfica abrange a bibliografia já publicada sobre o tema em estudo. Já a pesquisa documental será feita através da análise de documentos do setor de licitações da universidade.

Neste estudo, utilizando-se da pesquisa bibliográfica e documental, abordou o tema licitação, delimitando para os procedimentos na contratação de serviços terceirizados, com dedicação exclusiva de mão de obra, objetivando descrever as regras que asseguram as condições de igualdades entre os participantes. E ainda, levantaram-se conceitos sobre licitação, como também um breve histórico das contratações no setor público e por fim expôs as legislações e instrumentos regulatórios da licitação pública. 
Esse trabalho se justifica, em razão da existência de pouca divulgação sobre a estrutura burocrática necessária para a realização do processo de contratação pública.

Dentre os processos de contratação de terceirizados, disponibilizados para pesquisa, na Diretoria de Licitação e Contratos (DLC/PROGEST), escolheu para análise de estudo, o processo licitatório para a contratação de empresa a prestar os serviços de ascensoristas do Centro de Filosofia e Ciências Humanas $(\mathrm{CFCH})$, em razão deste processo ser a contratação de serviços de média qualificação profissional e envolver poucos profissionais para sua execução.

A pesquisa, no processo tomado como objeto de estudo, procurou verificar a aplicação das regras definidas nos instrumentos reguladoras da contração pública, para isso analisou o Termo de Referência, documento fundamental para elaboração do edital da licitação, as etapas e fases do processo licitatório, observando desde a sua abertura até a formalização do contrato com a empresa vencedora do certame. Feito estas análises foi possível elaborar uma tabela com as principais etapas do processo de contratação da empresa para a prestação do serviço de ascensorista.

Com a finalidade de comparar o tempo decorrido no evento do processo, que foi escolhido para análise, outros processos de terceirização, demandados de diferentes áreas, foram objeto da pesquisa e assim elaborou um quadro com o tempo gasto em cada evento da licitação de contratação de terceiros.

\section{CASO PRÁTICO DE UM PROCESSO LICITATÓRIO}

Como caso prático, foi escolhido para estudo o processo de terceirização dos serviços de ascensorista, analisando os procedimentos desde a fase preparatória até a formalização do contrato. A escolha desse processo se deu em razão de suas particularidades, por ser uma contratação de um serviço a ser prestado com qualificação técnica simples e por não haver ocorrências de fatos complexos no decorrer da licitação, permitindo apresentar de forma mais clara o procedimento prévio à contratação.

\section{ABERTURA DO PROCESSO DE LICITAÇÃO}

A partir da existência da necessidade pública a ser atendida, os atos de licitação desenvolvem-se numa sequência lógica, em duas fases: interna e externa. Deste modo, segundo Faria e Oliveira (2016), inicia o procedimento com o planejamento da contratação do serviço ou aquisição, prosseguindo até a assinatura do contrato ou emissão de documento equivalente (nota de empenho, autorização de fornecimento).

$\mathrm{Na}$ fase interna ou preparatória, desenvolvida no âmbito interno da Administração, inicia-se pela solicitação da unidade demandante que deverá justificar e definir o objeto da sua necessidade, estimar os custos e destacar a necessidade da reserva orçamentária para tal contratação. Nesta fase são delimitadas e determinadas as condições do ato convocatório antes de torná-las públicas.

A fase externa é caracterizada pela publicação do aviso do edital e a disponibilização do instrumento completo aos interessados. O encerramento desta fase ocorre com a formalização da contratação do objeto licitado, em conformidade com as regras estabelecidas no edital da licitação.

A fim de verificar a aplicação teórica do processo licitatório para contratação de serviços, foi analisado o processo de terceirização dos serviços de operação e controle dos elevadores do Centro de Filosofia e Ciências Humanas (CFCH), no campus Recife da UFPE, que, por regra, seguiu uma série de procedimentos formais estabelecidos pela legislação 
pertinente para uma futura contratação, conforme os ensinamentos dos autores Oliveira, Almeida e Lopes (2013).

O processo licitatório para as contratações de serviços na UFPE desenvolve-se seguindo as etapas definidas pelos regulamentos legais. No caso das contratações de terceiros para realizar atividades essenciais ao cumprimento da missão institucional, conforme dispõe o Decreto $n^{\circ}$ 2.271/97, os atos da licitação se desenvolvem numa sequência lógica. Inicialmente, em conformidade com o parágrafo $3^{\circ}$, Art. $6^{\circ}$ da IN 02/2008, elabora o plano de trabalho justificando a necessidade do serviço, definindo o seu quantitativo e estimando o custo da contratação. Na estimativa do custo, o setor demandante da contratação deve realizar ampla pesquisa de preços no mercado, consultando empresas que oferecem o serviço a ser contratado. Feito o plano de trabalho, o ato seguinte é a elaboração do Termo de Referência que deve ser aprovado pela autoridade competente.

O Termo de Referência, conforme estabelece o Art. 15 da IN 02/2008, deve conter:

a) a justificativa da necessidade da contratação; a contratação;

b) o objetivo da contratação, identificando o que se pretende alcançar com

c) o objeto da contratação e os resultados esperados com a execução do serviço;

d) descrição detalhada dos serviços a serem executados, nomeando local e horário de funcionamento e disponibilidade orçamentária da instituição, nos termos do art. 12 da Lei $\mathrm{n}^{\circ}$ 8.666/93, e ainda definir a rotina de execução;

e) justificativa da relação entre a demanda e a quantidade de serviços a ser contratada e no que couber os critérios de medição a ser utilizados;

f) enquadramento como serviço comum para fins do disposto no art. $4^{\circ}$ do Decreto $\mathrm{n}^{\circ} 5.450 / 2005$;

g) quantitativo da contratação;

h) custo estimado da contratação, fundamentado por pesquisa de preços praticados no mercado em contratações similares;

i) produtividade de referência, quando cabível, levando-se em consideração as rotinas de execução, quantidade e qualificação de mão de obra estimada para o serviço, relação do material e equipamento e condições do local onde o serviço será realizado;

j) condições que possam ajudar na identificação do quantitativo de pessoal e insumos necessários;

k) deveres da contratada e da contratante;

1) acordo de níveis de serviços.

No processo de licitação, em estudo, a diretoria do Centro iniciou a abertura da licitação, que foi autuada sob no 23076.018646/2012-15, datado em 23/04/2012, solicitando à Diretoria de Orçamentos e Finanças da UFPE a dotação orçamentária para a realização das despesas com a contratação dos serviços.

O Termo de Referência foi elaborado em conformidade com a Lei 8.666/93, Lei 9.632/98, Decreto 2.271/97 e IN 02/2008, com revisão da Pró Reitoria de Gestão de Pessoas.

Assim, tem:

Justificativa: Prédio de 15 andares com três elevadores onde há uma estimativa de circulação diária de mais de 5.000 pessoas, situação que requer o serviço continuado de ascensorista que terá como função controlar a capacidade de carga dos elevadores, garantindo a segurança aos usuários, evitar danos a esses equipamentos e facilitar o fluxo de pessoas. 
Objetivo: A contratação dos serviços de ascensorista promoverá maior controle na capacidade de carga dos elevadores, garantir a segurança aos usuários, evitar danos nos equipamentos e facilitar o fluxo de pessoas.

Objeto: Contratação de pessoa jurídica especializada na prestação de serviços de controle e operação dos elevadores, ascensorista, do Centro de Filosofia e Ciências Humanas $\mathrm{CFCH}$, campus Recife UFPE.

Estimativo dos custos: O valor das despesas, para um período de 12 meses, foi estimado em $\mathrm{R} \$ 236.588,76$ (duzentos e trinta e seis mil quinhentos e oitenta e oito reais e setenta e seis centavos). Para chegar a este custo estimado, realiza-se uma pesquisa de preços com as empresas prestadoras do serviço a ser contratado, adotando-se a média dos valores pesquisados.

Quantitativo da Contratação: Definido em 12 Postos de Trabalhos, observando as ocasiões de maior fluxo de pessoas, de maneira a cobrir o funcionamento dos elevadores.

O Decreto $\mathrm{n}^{\circ}$ 5.450/2005 estabelece, no seu Art. $4^{\circ}$, a obrigatoriedade da licitação na modalidade Pregão para aquisição de bens e serviços comuns. Neste caso, o setor demandante ratificou que o serviço de ascensorista se enquadra como comum e assim solicitou adotar a modalidade Pregão Eletrônico e tipo menor preço.

Com base no Termo de Referência, foi elaborado o instrumento convocatório da licitação, denominado Pregão Eletrônico nº 244/2012, e com sua publicação, os interessados tiveram acesso ao edital contendo todos os requisitos para a contratação pública.

Na publicação do Edital do Pregão Eletrônico são definidos o horário da abertura da sessão e os prazos para apresentarem as propostas. A sessão de abertura Pregão Eletrônico acontece no site de compras do Governo Federal (www.comprasnet.gov.br), tipo sala de batepapo da internet, onde as propostas enviadas pelos concorrentes são abertas e o Pregoeiro divulga os valores (lance inicial) para todos os participantes.

Examinando a Ata da Sessão do Pregão, com a participação de 13 empresas, verifica-se que os lances iniciais têm valores de $\mathrm{R} \$ 214.692,12$ a $\mathrm{R} \$ 1.200 .00,00$. Importante observar que a proposta de menor valor representa $90,7 \%$ do custo estimado.

O pregão é como um leilão invertido, ganha quem oferece o menor preço pelo bem ou serviço, mas a identidade dos autores dos lances não é revelada aos outros participantes.

Com a fixação da menor proposta, o Pregoeiro estimula os concorrentes a fazer lances até não ter mais propostas e a de menor lance, antes do ato de adjudicação, é remetida para a equipe técnica de contabilidade analisar as planilhas de custo e formação de preços e Demonstrações Contábeis exigidas pelo Edital. Qualquer inconsistência técnica é sanada por meio do procedimento de diligência e caso a empresa não corrija as planilhas, a proposta é desclassificada e nova proposta passa a ser objeto de análise da equipe técnica contábil.

A proposta vencedora deste certame foi no valor $\mathrm{R} \$ 193.473,24$, representando cerca de $82 \%$ do valor estimado, uma economia para o governo de $\mathrm{R} \$ 43.115,52$, ou seja, cerca de $18 \%$ do custo estimado.

O Quadro 3 apresenta um resumo da competição do certame. Nota-se o interesse das empresas em prestar serviços ao governo quando 16 empresas retiraram o edital e a maioria apresentou propostas na seção de abertura do Pregão. Foram 13 empresas que iniciaram os lances da disputa para prestar o serviço de ascensorista. Os dados do Quadro 3 mostram, que no primeiro lance (abertura das propostas), a competição já apresentava uma economia de $9,255 \%$ que ao longo da sessão de lances chegou a 18,223\%, proporcionando uma economia em dobro para o Serviço Público. 
Quadro 3. Resumo da Licitação Pregão Eletrônico 244/2012

\begin{tabular}{|l|c|c|c|}
\hline & $\begin{array}{c}\text { Empresas } \\
\text { Participantes }\end{array}$ & Custos & Economia \\
\hline Retiraram Edital & 16 & & \\
\hline Apresentaram Propostas & 13 & $\mathrm{R} \$ 236.588,76$ & \\
\hline Valor Estimado & & $\mathrm{R} \$ 214.692,12$ & $\mathrm{R} \$ 21.896,64(9,255 \%)$ \\
\hline $\begin{array}{l}\text { Menor Valor na abertura das } \\
\text { Propostas }\end{array}$ & & $\mathrm{R} \$ 193.473,24$ & $\mathrm{R} \$ 43.115,52$ \\
\hline Valor da Proposta Vencedora & & & $(18,223 \%)$ \\
\hline
\end{tabular}

Fonte: Autoria própria com dados da DLC/PROGEST

Na licitação modalidade Pregão Eletrônico, o ato de adjudicação é realizado pelo Pregoeiro e a homologação do processo é feita pela autoridade competente da Instituição promotora da licitação e assim o processo licitatório se encerra e a administração contrata o objeto licitado. No caso em estudo, a empresa vencedora celebrou o contrato para prestar os serviços de controle e operação dos elevadores do Centro de Filosofia e Ciências Humanas da UFPE, constituindo uma terceirização de atividades de apoio da Universidade, necessárias ao desenvolvimento das suas atividades principais.

Para concluir a análise do processo de licitação Pregão Eletrônico nº 244/2012, o Quadro 4 foi construído para mostrar o tempo decorrido entre a solicitação da contratação e a efetivação do contrato celebrado com a empresa vencedora da licitação. Na construção desse quadro, contabilizou-se o tempo decorrido entre os eventos subsequentes, considerando como ponto de partida a data de abertura do processo administrativo, ou seja, o dia em que o processo foi autuado e registrado no sistema de protocolo da universidade. Considerando o período, da data de abertura do processo até a data da assinatura do contrato, a licitação, para contratar empresa para prestar os serviços de ascensoristas, foi concluída em 361 dias, praticamente um ano.

Quadro 4. Tempo decorrido entre os eventos da licitação Pregão Eletrônico no 244/2012

\begin{tabular}{|l|c|}
\hline \multicolumn{1}{|c|}{ Eventos } & Tempo decorrido (dias) \\
\hline Aprovação do Termo de Referência & 128 \\
\hline Aprovação do Edital & 56 \\
\hline Publicação do Edital & 36 \\
\hline Abertura do Pregão Eletrônico & 15 \\
\hline Encerramento da Sessão do Pregão e Adjudicação do Vencedor & 89 \\
\hline Homologação do Resultado do Pregão Eletrônico & 2 \\
\hline Assinatura do Contrato & 35 \\
\hline
\end{tabular}

Fonte: Autoria própria com dados da DLC/PROGEST

Nota. Processo formalizado em 23/04/2012

De acordo com o Quadro 4, o evento que consumiu maior tempo para sua conclusão foi o Termo de Referência, tendo gasto 128 dias para sua aprovação. Isto mostra que elaborar o Termo de Referência é uma tarefa complexa, porque é neste documento que o objeto da contratação é definido e especificado de forma precisa, cabendo à área requisitante a responsabilidade pela sua elaboração, conforme disposição no inc. I do art. $9^{\circ}$ do Decreto $\mathrm{n}^{\circ}$ $5.450 / 2005$. Em certos casos, acontece que o objeto a ser contratado envolve especificações técnicas que a área requisitante não tem condições de especificar, necessitando, neste casso, recorrer ao auxílio de terceiros, como no caso de contratação de serviços terceirizados, com o uso exclusivo de mão de obra, necessita de especificar se na execução dos serviços, o 
trabalhador faz jus aos adicionais de insalubridade ou periculosidade, onde somente com um laudo técnico, elaborado por profissional especializado, é que se pode definir tal situação.

Esta delonga, na aprovação do Termo de Referência, não é um caso especifico do processo de licitação analisado. Em outros processos, também foi observado esta demora, conforme se pode verificar pelos dados do Quadro 5 que será apresentado e estudado na próxima seção.

\section{ANÁLISE DO PROCESSO DE LICITAÇÃO PARA SERVIÇOS TERCEIRIZADOS DA UFPE}

A Administração nem sempre dispõe de meios próprios para atender as necessidades de interesse público, sendo obrigada a contratar terceiros para executar parte dessas atividades e somente pode realizar essas contratações por intermédio de licitação pública, em que seja assegurada a igualdade de condições entre os concorrentes.

As normas para licitações e contratos públicos apresentam vários princípios que devem ser observados na realização do processo licitatório, para isso a Divisão de Licitações da UFPE (DLIC) cumpre uma série de procedimentos estabelecidos pela legislação, e que demandam tempo. Para facilitar a visão dos procedimentos, no processo de licitação, a Figura 1 mostra o curso de uma licitação, a partir da necessidade da contratação/aquisição da Administração até o seu desfecho.

Figura 1. Fluxo do processo de licitação

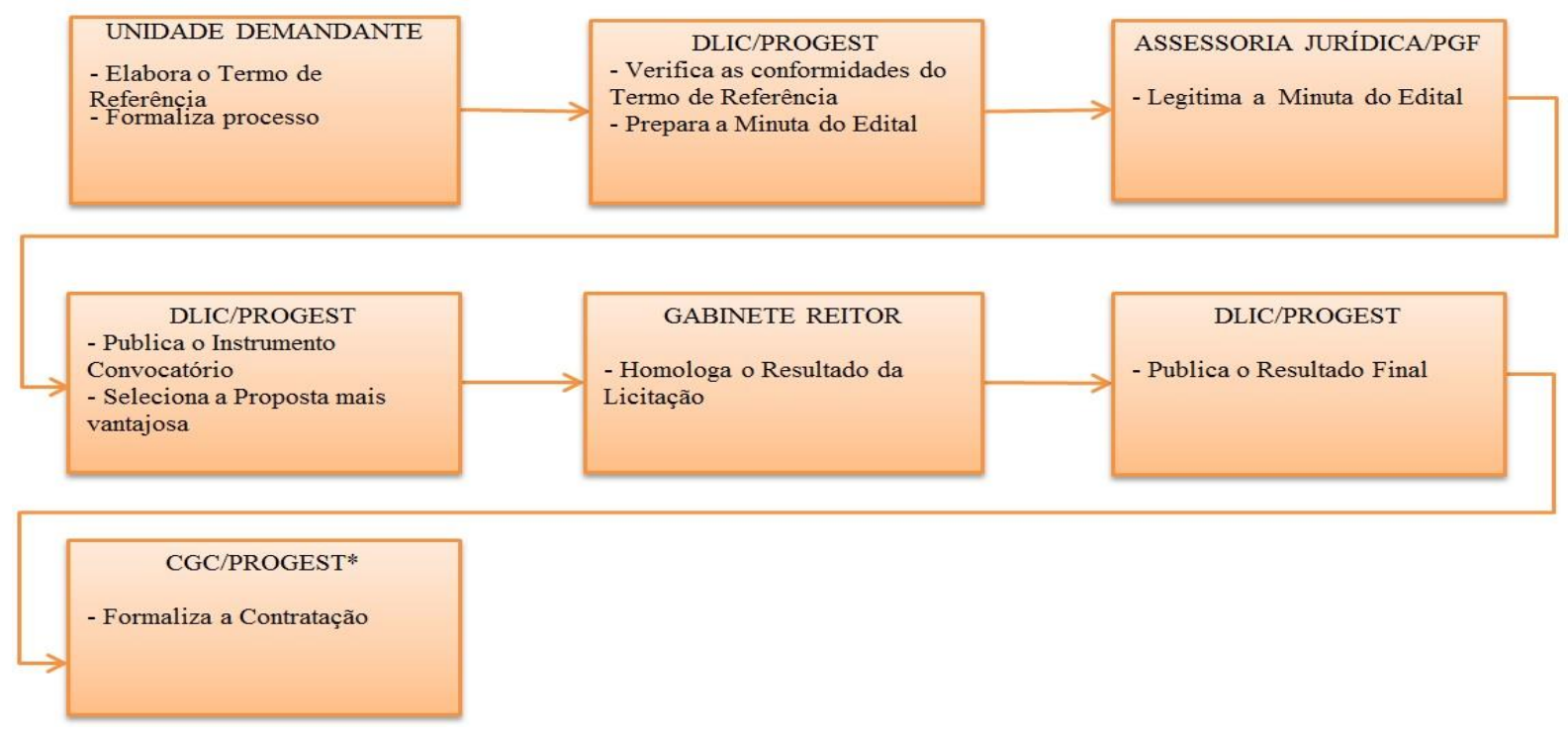

Fonte: Autoria própria com dados da DLC/PROGEST Nota. CGC: Coordenação de Gestão de Contratos

Os processos de licitação, a partir da formalização pela Unidade Demandante, seguem o fluxo mostrado pela Figura 1 e são realizados pela Divisão de Licitações (DLIC), em sua maioria na modalidade Pregão Eletrônico.

A DLIC é uma divisão da Diretoria de Licitações e Contratos (DLC) que é uma unidade administrativa subordinada à Pró Reitoria de Gestão Administrativa (PROGEST) da Universidade Federal de Pernambuco. 
Com sua equipe de apoio e pregoeiros, designados pela Administração, a DLIC recebe as demandas de licitações para elaborar os instrumentos convocatórios, editais e conduzir a abertura e encerramento dos processos licitatórios, observando os princípios legais com vistas ao atendimento do interesse público.

Para quem lida, no dia a dia, com as licitações sabe o muito que se tem a fazer antes da divulgação do edital. É esse o trabalho da equipe da DLIC, mostrado na Figura 1, que na fase inicial analisa o Termo de Referência (TR) ou Projeto Básico (PB) elaborado pela área requisitante. A análise do TR/PB é focada na especificação do objeto, no valor estimado da futura contratação, na pesquisa de preços praticados no mercado, na existência da dotação orçamentária e nas condições de execução do objeto. Havendo inconsistências no TR/PB, a DLIC retorna o processo de licitação à área requisitante para ajustes e assim poder prosseguir com a elaboração do edital.

Por esses motivos é que o Termo de Referência leva mais de quatro meses para ser aprovado, conforme dados apresentados no Quadro 5. Em alguns processos de licitação que foram analisados, observou-se que o TR foi refeito por mais de uma vez. Sendo um requisito fundamental da fase interna da licitação, o TR/PB irradia efeitos em toda contratação, por isso suas deficiências ou omissões podem lograr a licitação ou ainda permitir vícios ou falhas no curso do contrato administrativo.

Quadro 5. Tempo decorrido entre os eventos no Processo de Licitação de Serviços Terceirizados

\begin{tabular}{|l|c|c|c|c|}
\hline \multicolumn{1}{|c|}{ Pregões } & PE & $\begin{array}{c}\text { PE } \\
12 / 2016\end{array}$ & $\begin{array}{c}\text { PE } \\
176 / 2013\end{array}$ & $\begin{array}{c}\text { PE } \\
\text { Eventos }\end{array}$ \\
\hline Abertura do Processo & $09 / 06 / 2015$ & $11 / 03 / 2015$ & $03 / 04 / 2013$ & $06 / 09 / 2013$ \\
\hline Aprovação do Termo de Referência & 287 & 317 & 135 & 202 \\
\hline Aprovação do Edital & 15 & 3 & 69 & 144 \\
\hline Publicação do Edital & 8 & 2 & 7 & 112 \\
\hline Abertura do Pregão Eletrônico & 14 & 15 & 70 & 10 \\
\hline $\begin{array}{l}\text { Encerramento da Sessão do Pregão e } \\
\text { Adjudicação do Vencedor }\end{array}$ & 98 & 183 & 33 & 169 \\
\hline $\begin{array}{l}\text { Homologação do Resultado do Pregão } \\
\text { Eletrônico }\end{array}$ & 0 & 3 & 37 & 24 \\
\hline Assinatura do Contrato & 25 & 14 & 7 & 59 \\
\hline Tempo Total & 447 & 537 & 358 & 696 \\
\hline Média 509,5 dias & & & \\
\hline
\end{tabular}

Fonte: Autoria própria com dados da DLC/PROGEST

Nota. PE 13/2016 Limpeza e Conservação Predial - Campus Vitória. PE 12/2016 Limpeza e Conservação Predial - Campus Caruaru. PE 176/2013 Serviços de Vigilância Armada - UFPE. PE 256/2014 Serviços de Contínuos - Campus Recife

Todo esse procedimento realizado pela DLIC é com o objetivo de resguardar o cumprimento das normas legais e permitir que a administração celebre contratações vantajosas para o serviço público.

De acordo com a Figura 1, o processo de licitação tem o seu fluxo constituído em sete etapas, onde na sexta etapa é concluído pela DLIC com a publicação do Resultado Final. A formalização da contratação do objeto licitado é feita pela Coordenação de Gestão de Contratos (CGC), divisão da DLC que é responsável pela elaboração do documento de contratação.

Com a finalidade de verificar o tempo decorrido em outros processos de contratação de serviços terceirizados, montou-se o Quadro 5 com os mesmos eventos relacionados no Quadro 4, extraindo os dados de processos com diferentes áreas requisitantes. Em todos os processos 
analisados, o Termo de Referência levou mais de quatro meses para ser aprovado, consequentemente esse tempo repercute na conclusão do processo. É o que se pode observar, no Quadro 5, o resultado da análise do Pregão Eletrônico $n^{\circ} 176 / 2013$, que foi o processo de licitação concluído com o menor tempo, apresentando, também, entre os processos analisados o menor tempo para aprovar o TR.

Dos dados levantados no Quadro 5, é importante observar o tempo que se leva para encerrar a sessão do Pregão e adjudicar o vencedor do certame. Como se sabe, após a abertura das propostas inicia-se a fase dos lances, havendo uma intensa disputa pelo objeto da licitação. Não existindo outros lances que cobre o de menor valor, o pregoeiro encerra a sessão, habilita a proposta de menor lance e abre o prazo recursal. Caso não haja interposição de recurso, de imediato, o pregoeiro adjudica o vencedor.

Havendo a manifestação do licitante de interpor recurso, este será analisado pelo pregoeiro que diante de qualquer decisão tem que encaminhar o processo para deliberação da autoridade competente, onde há um procedimento legal a cumprir e que pode consumir um tempo razoável para a decisão final.

Nos pregões analisados, o tempo para encerrar a sessão de abertura e adjudicar o vencedor foi uma média de 120,7 dias, cerca de quatro meses. Quanto ao tempo para encerrar todo o processo, desde a sua abertura até a celebração do contrato, a média foi de 509,5 dias, aproximadamente um ano e cinco meses.

Essa média de tempo gasto para concluir os processos de licitações dos serviços terceirizados, reforça o entendimento de Faria e Oliveira (2016) sobre os procedimentos para contratações públicas que são lentos e onerosos e que as licitações são conhecidas pela burocracia e morosidade.

Os dados registrados no Quadro 5 indicam que a UFPE leva um tempo médio próximo de 8 meses para aprovar um Termo de Referência e um ano e cinco meses para concluir a licitação dos serviços terceirizados.

\section{CONSIDERAÇÕES FINAIS}

Este trabalho mostrou que as condições de igualdades entre os concorrentes, na licitação pública, são asseguradas por regras estabelecidas em lei e garante a observância dos princípios constitucionais, a saber: legalidade, impessoalidade, moralidade, publicidade e eficiência.

Com base nas referências bibliográficas, constatou que a regulamentação da licitação, através da Lei $\mathrm{n}^{\circ}$ 8.666/93, possibilitou a participação de maior número de concorrentes no processo das contratações governamental. Os procedimentos definidos nessa lei e em outras legislações complementares permitem a todos a oportunidade de contratar com a Administração Pública, desde que atendem os requisitos estabelecidos no edital do processo licitatório.

Devido ao ritual estabelecido na Lei 8.666/93, a licitação ficou conhecida como burocrática e morosa. Assim, para amenizar a burocracia e dar maior agilidade nas licitações públicas, foi instituído o Pregão, como uma nova modalidade de licitação, para amenizar a burocracia e agilizar a licitação pública.

Neste estudo, constatou que o Pregão trouxe ganhos para o processo de contratações, como a redução do tempo entre a publicidade e a abertura das propostas. Na modalidade pregão, primeiro analisa os preços para depois analisar a qualificação dos participantes do certame e assim, somente é analisada a documentação da empresa que apresentou a melhor proposta. Outro ganho foi o uso da tecnologia, passando o Pregão a ser realizado através da rede da Internet, permitindo ao licitante participar da licitação pública sem a necessidade de se deslocar para o local do órgão público, promotor da licitação. 
Por meio da análise realizada nos processos de licitação, destinados a contratações de serviços terceirizados, com dedicação exclusiva de mão de obra, na Universidade Federal de Pernambuco, demonstrou, na prática, algumas vantagens apontadas pelas referências bibliográficas, como: planejamento da licitação, que na modalidade Pregão requer o Termo de Referência com os detalhes do objeto a ser contratado; maior número de empresas participantes e maior competividade (todas as empresas credenciadas participam da oferta de lances).

Não restam dúvidas que o Pregão Eletrônico, como uma nova modalidade de licitação, amenizou a burocracia e deu agilidade nas licitações, como a redução do tempo entre a publicidade e a abertura das propostas cujas aberturas são realizadas sem a prévia análise da documentação comprobatória da regularidade fiscal e econômica dos licitantes.

Mesmo com esses ganhos, a licitação Pregão Eletrônico ainda continua com um razoável tempo para conclusão. Nos processos analisados, o tempo médio para encerrar a sessão de abertura e adjudicar o vencedor foi em torno de quatro meses e para o encerramento do processo foi de um ano e cinco meses. Um tempo longo que pode afetar os objetivos do planejamento da contratação, definido na fase inicial do processo.

Ao finalizar este trabalho, cumprindo os objetivos propostos, espera-se ter contribuído como fonte de referência bibliográfica e fonte de discussão a respeito das contratações públicas e processos de terceirizações nas instituições federais de ensino superior. No entanto, este trabalho não esgota os estudos e resultados sobre o tema, tendo em vista a intensa competição em apresentar a melhor proposta a ser escolhida pela Administração Pública, abre-se um campo para que novas pesquisas possam ser desenvolvidas sobre o tema e aprofundar o conhecimento a respeito da economicidade das contratações públicas.

\section{REFERÊNCIAS}

BRASIL. Decreto Lei nº 200, de 1967. Dispõe Sobre a Organização da Administração Federal, Estabelece Diretrizes para a Reforma Administra. Lex. Brasilia.

Decreto ${ }^{\circ}$ 2.271, de 7 de julho de 1997. Dispõe Sobre a Contratação de Serviços pela Administração Pública Federal Direta, Autárquica e Fundacional e Dá Outras Providências. Lex. Brasília.

BRASIL. Decreto-Lei n ${ }^{\circ} 2.300$, de 21 de novembro de 1986. Dispõe sobre licitações e contratos da Administração Federal e dá outras providências. Lex. Brasilia, DF.

Decreto $n^{\circ}$ 5.450, de 31 de maio de 2005. Regulamenta o Pregão, na Forma Eletrônica, para Aquisição de Bens e Serviços Comuns, e Dá Outras Providências. Lex. Brasilia, DF.

Lei $n^{\circ}$ 8.666, de 21 de junho de 1993. Regulamenta o art. 37, inciso XXI, da Constituição Federal, institui normas para licitações e contratos da Administração Pública e dá outras providências. Lex

.. Lei $\mathrm{n}^{\circ} 10.520$, de 17 de julho de 2002. Institui, no âmbito da União, Estados, Distrito Federal e Municípios, nos termos do art. 37, inciso XXI, da Constituição Federal, modalidade de licitação denominada pregão, para aquisição de bens e serviços comuns, e dá outras providências. Lex. Brasilia 
ENAP, Fundação Escola Nacional de Administração Pública. Legislação Aplicada à Logística de Suprimentos Lei no 8.666/93, pregão e registro de preços, Módulo 1 A Importância e Necessidade da Lei de Licitações, Brasília, 2014. Disponível em $<$ http://repositorio.enap.gov.br/handle/1/858>. Acesso em 10 out 2017.

FARIA, Messias Anain Almeida; OLIVEIRA, Ionara Lúcia de Melo Castro. Licitação Pública: Análise da Utilização da Modalidade Pregão Na Forma Eletrônica - Pregão Eletrônico. Revista Eletrônica de Educação da Faculdade Araguaia, Goiânia, v. 9, p.349 -366, jun. 2016. Semestral. <http://www.faculdadearaguaia.edu.br/sipe/index.php/renefara/issue/view/33>. Acesso em 04 out. 2017.

FONSECA, Albérico Santos. Fases de uma Licitação. Material didático da disciplina Bases Procedimentais da Administração Pública - Faculdade Paraibana - Curso de Direito, 2014.1 João Pessoa, PB: [s.n], 2014.1

FONSECA, Novânia Nunes; GUSINSKY, Matheus Nunes; BERNARDES, José Francisco. Vantagens do Pregão Eletrônico no Setor Público. In: XIV COLÓQUIO INTERNACIONAL DE GESTÃO UNIVERSITÁRIA - CIGU, 14., 2014, Florianópolis - Sc. Anais... Florianopolis - Sc: A GestÃo do Conhecimento e Os Novos Modelos de Universidade, 2014. p. 1 - 17. Disponível em: <http://www.repositorio.ufsc.br.>. Acesso em: 15 out. 2017.

GIL, Antonio Carlos. Como Elaborar Projetos de Pesquisa. 4. ed. São Paulo: Atlas, 2002.

LICITACAO.NET.Como fazer Licitação. Disponível em <https://www.licitacao.net/como_fazer_as_licitacoes.asp>. Acesso em 16 mar 2018.

MINISTÉRIO DO PLANEJAMENTO ORÇAMENTO E GESTÃO. Instrução Normativa ${ }^{\circ}$ 02, de 30 de abril de 2008. Dispõe sobre regras e diretrizes para a contratação de serviços, continuados ou não. In. Brasília, DF,

OLIVEIRA, Ari Eduardo de; ALMEIDA, Damiana Machado de; LOPES, Luis Felipe Dias. Processo Licitatório de Bens, Obras e Serviços do Poder Público e Seus Princípios Norteadores. Revista Pensamento \& Realidade, São Paulo -sp, v. 28, n. 1, p.144-164, abr. 2013. Quadrimestral. Disponível em: <https://revistas.pucsp.br/index. php/pensamentorealidade/issue/view/1074>. Acesso em: 14 out. 2017.

REITZ JÚNIOR, Nilson; BOSELLI, Felipe. Planejamento Administrativo para Contratação de Bens e Serviços Usuais na Administração Pública. Revista Empreendorismo e Sustentabilidade - 2016, São José - Sc, v. 1, n. 1, p.45-63, dez. 2016. Anual. Disponível em: <http://www.icepsc.com.br/ojs/index.php/empreendedorismo/index $>$. Acesso em: 08 out. 2017.

SANTANA, Jair Eduardo. Licitação e Contratação de Serviços continuado ou Não - A Instrução Normativa 02/2008 - SLTI/MPOG. O Pregoeiro, Curitiba - Pr, v[ni] , n[ni]. , p.1825, jun. 2008.

SILVA, Maria de Fátima N. da; CARVALHO, Maria Balbina de. A Gestão de Compras e o Processo de Licitação no Setro Público. Cadernos de Graduação: Ciências Humanas e 
Sociais, Aracaju, v. 4, n. 1, p.165-178, mar. 2017. Disponível em: <https://periodicos.set.edu.br/index.php/cadernohumanas>. Acesso em: 04 out. 2017.

TRIBUNAL DE CONTAS DA UNIÃO. Licitações e contratos: orientações e jurisprudência do TCU. 4. ed. Brasília - Df: TCU, 2010. Disponível em: 〈www.tcu.gov.br>. Acesso em: 18 out. 2017. 